\title{
Calvarium and dura mater as delayed sites of distant metastasis from papillary thyroid carcinoma
}

This article was published in the following Dove Press journal:

International Medical Case Reports Journal

16 October 2015

Number of times this article has been viewed

\author{
Khalid Hussain AL-Qahtani' \\ Mutahir A Tunio² \\ Mushabbab Al Asiri ${ }^{3}$ \\ Hanadi Fatani ${ }^{4}$ \\ Yasser Bayoumi ${ }^{5}$ \\ 'Department of Otolaryngology- \\ Head and Neck Surgery, College \\ of Medicine, King Saud University, \\ ${ }^{2}$ Radiation Oncology Department, \\ King Fahad Medical City, \\ ${ }^{3}$ Radiation Oncology Department, \\ ${ }^{4}$ Histopathology Department, \\ Comprehensive Cancer Center, \\ King Fahad Medical City, Riyadh, \\ Saudi Arabia; ${ }^{5}$ Radiation Oncology \\ Department, National Cancer \\ Institute, Cairo, Egypt
}

Background: Skull calvarium and dura mater are rare sites of distant metastasis, and mostly have been reported in lung, breast, and prostate malignancies. However, the calvarial and dural metastases from papillary thyroid cancer (PTC) are rare entities and pose diagnostic and therapeutic challenges. To date, only seven cases of calvarial metastasis with intracranial extension from PTC have been reported in literature. However, true dural metastasis from PTC has not yet been reported.

Case presentation: A 65-year-old Saudi woman presented with 6 months history of painful posterior scalp lump, 7 years after initial diagnosis of PTC. Computed tomography and magnetic resonance imaging showed occipitoparietal calvarial lesion with massive intracranial extension. Another para-sagittal lesion was found at the top of corpus callosum mimicking a meningioma. Histopathology of para-sagittal lesion and the biopsy of calvarial mass confirmed the diagnosis of metastatic PTC. After surgical resection, residual tumors were treated with postoperative intensity-modulated radiation therapy. At 13 months of follow-up, patient was alive and without any signs of recurrence.

Conclusion: Calvarial and dural metastases from PTC are extremely rare clinical entities. Surgical resection followed by postoperative radiotherapy is the treatment of choice. However, for such cases, multidisciplinary approach can prolong the treatment outcome and survival.

Keywords: papillary thyroid carcinoma, calvarial metastasis, intracranial extension, true dural metastasis

\section{Introduction}

Differentiated thyroid cancer, especially papillary thyroid cancer (PTC), commonly metastasizes to regional lymph nodes, lungs, and bones. However, the skull is uncommon site of metastasis, being involved only in $2.5 \%-5.8 \%$ of the cases. ${ }^{1}$ Skull metastasis from PTC is frequently reported in the skull base, and the calvarial metastasis is a rare entity. ${ }^{2}$ Calvarial metastasis from PTC usually presents as painless extracranial soft tissue mass, and in a few cases with intracranial extension, which is considered as indicator of poor prognosis. ${ }^{3}$ So far, true dural metastasis from PTC is not known in the literature; however, only one case of true dural metastasis mimicking a meningioma from follicular thyroid carcinoma has been reported previously. ${ }^{4}$ Symptoms of calvarial and dural metastases may vary from asymptomatic to recurrent headaches, seizures, sensory-motor dysfunction, and stroke, depending on the site of dural metastasis and extent of intracranial extension in calvarial metastasis. ${ }^{5,6}$

In this study, we describe a 65 -year-old female with occipitoparietal calvarial metastasis with massive intracranial extension and para-sagittal dural metastasis from PTC.
Correspondence: Mutahir A Tunio Radiation Oncology Department, Comprehensive Cancer Center, King Fahad Medical City, Riyadh 59046, Saudi Arabia

Tel/fax +966 I2889999

Email mkhairuddin@kfmc.med.sa 


\section{Case presentation}

In December 2013, a 65-year-old Saudi woman presented to us with the complaint of painful lump over the occipital region of scalp. She had noticed this lump for 6 months and it was increasing in size over 2 months; she was taking nonsteroidal anti-inflammatory drugs but with minimal improvement. Her previous medical history was not significant, and she denied any history of trauma, smoking, or weight loss. Past surgical history revealed that she had undergone total thyroidectomy and lymph node dissection for follicular variant papillary thyroid carcinoma $\mathrm{pT} 2 \mathrm{~N} 1 \mathrm{bM} 0$ in June 2006. Postoperative thyroglobulin (TG) was $2.4 \mathrm{ng} / \mathrm{mL}$. Subsequently, the patient was given radioactive iodine ablation $150 \mathrm{mCi}$ in August 2006.

On physical examination, she was found to be in good general condition, and her vitals were stable. Head and neck examination revealed a hard fixed and tender mass of size $4 \mathrm{~cm} \times 4 \mathrm{~cm}$ in the occiput without any ulceration of overlying skin, and the rest of the systemic examination was unremarkable. Clinical differential diagnosis was meningioma, sarcoma, giant cell tumor, or metastasis.

Hematology, renal and liver function tests, serum electrolytes, thyroid-stimulating hormone, and thyroxin were found to be within normal limits. Serum TG levels were markedly elevated, ie, $3,064 \mathrm{ng} / \mathrm{mL}$ (normal: 5-25 ng/mL). Whole body iodine scintigraphy was nonavid. Head and neck computed tomography $(\mathrm{CT})$ showed a large left occipital bone mass of size $5.7 \mathrm{~cm} \times 1.9 \mathrm{~cm}$ with intracranial extension and was extending superiorly to involve the parietal bone. Another intracranial dural-based lesion of size $2.6 \mathrm{~cm} \times 2.3 \mathrm{~cm}$ was also found at the top of the splenium of corpus callosum (Figure 1A and B). Magnetic resonance imaging (Figure 2) and CT-positron emission tomography confirmed the findings of CT imaging. Fine needle aspiration of calvarial lesion confirmed the malignant follicular cells of PTC.

The patient was operated in January 2014; however, surgical attempt for complete resection of both lesions was foiled by perioperative profuse bleeding. Histopathology of the dural lesion revealed follicular pattern with numerous colloid-filled follicles with characteristic nuclear features of papillary carcinoma (enlarged and elongated nuclei and nuclear grooves), and immunopositivity for thyroid transcription factor-1 and cytokeratin 19 confirmed the diagnosis of metastatic follicular variant PTC (Figure 3). Genetic testing revealed a BRAF V600E mutation. After successful recovery, patient was treated with intensity-modulated radiation therapy. Total dose of 5,400 cGy in 27 fractions over 6 weeks was given to both lesions. The treatment course was
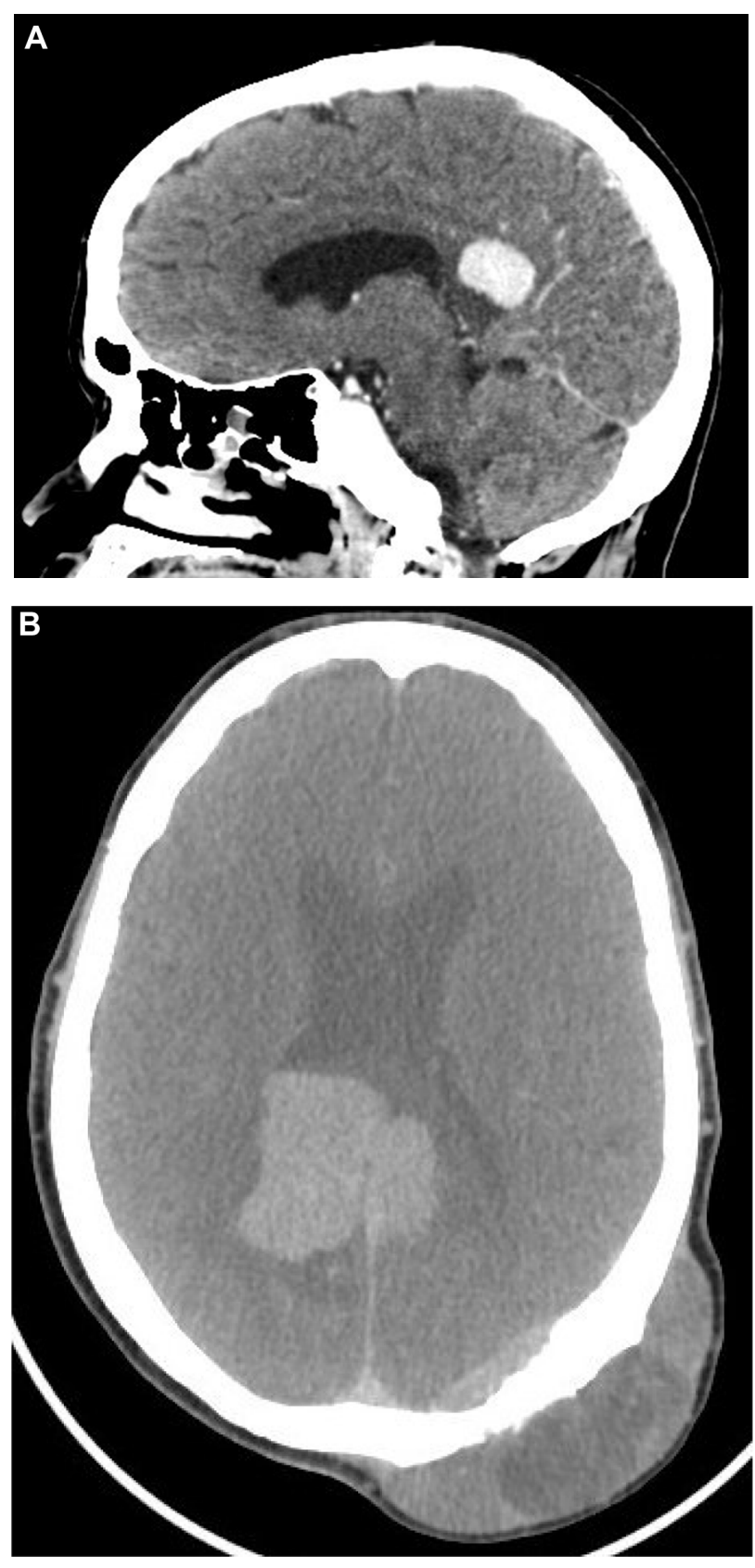

Figure I Head and neck computed tomography.

Notes: (A) Sagittal image showing intracranial dural lesion of size $2.6 \mathrm{~cm} \times 2.3 \mathrm{~cm}$ at the top of splenium of corpus callosum and (B) axial image showing a large left occipital bone mass of size $5.7 \mathrm{~cm} \times 1.9 \mathrm{~cm}$ with intracranial extension, and parasagittal dural-based lesion was thought to be a meningioma.

completed without any significant acute toxicity. Due to radioactive iodine refractory disease, the patient was started on sorafenib (Nexavar; Onyx Pharmaceuticals, Emeryville, CA, USA, and Bayer Healthcare, Wayne, NJ, USA) $400 \mathrm{mg}$ orally twice daily after the completion of radiation therapy. At 8 months of follow-up period, the patient was doing well with stable skull mass and decreasing pattern of TG levels (37 ng/mL). 


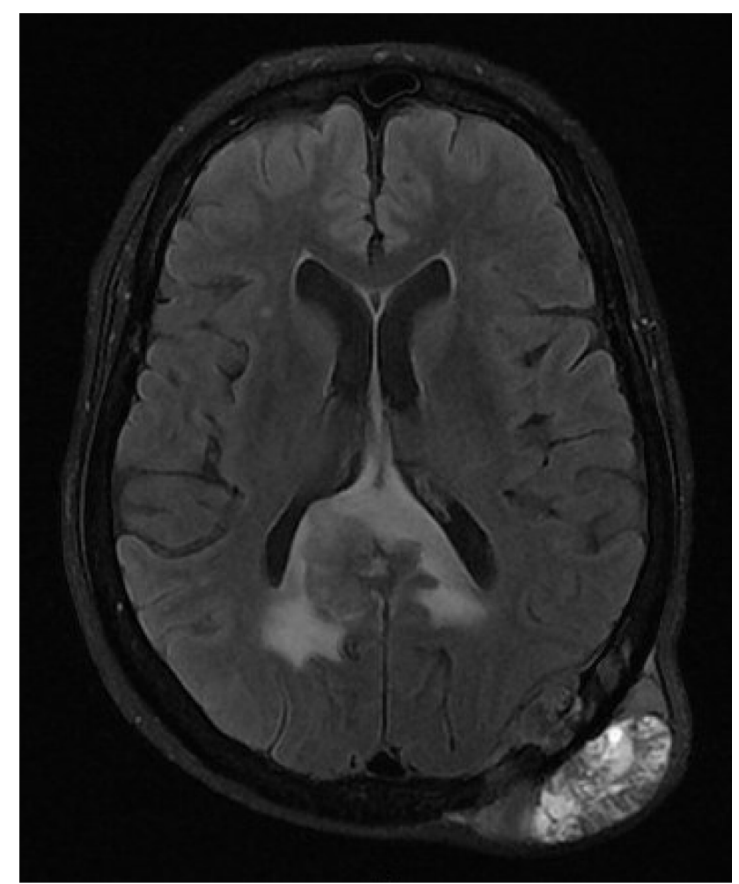

Figure 2 Magnetic resonance imaging (T2-weighted axial image) showing diffuse dural mass and another large lesion in the left occipitoparietal bone with intracranial extradural, intraosseous, and subgaleal soft tissue components.

\section{Discussion}

Calvarium and dura as initial sites of distant metastasis from PTC is extremely rare. To date, only seven cases of calvarial metastasis with massive intracranial extension to involve dura from PTC have been published (Table 1). ${ }^{3,5,7-11}$ In our patient, calvarial metastasis with intracranial extension was seen

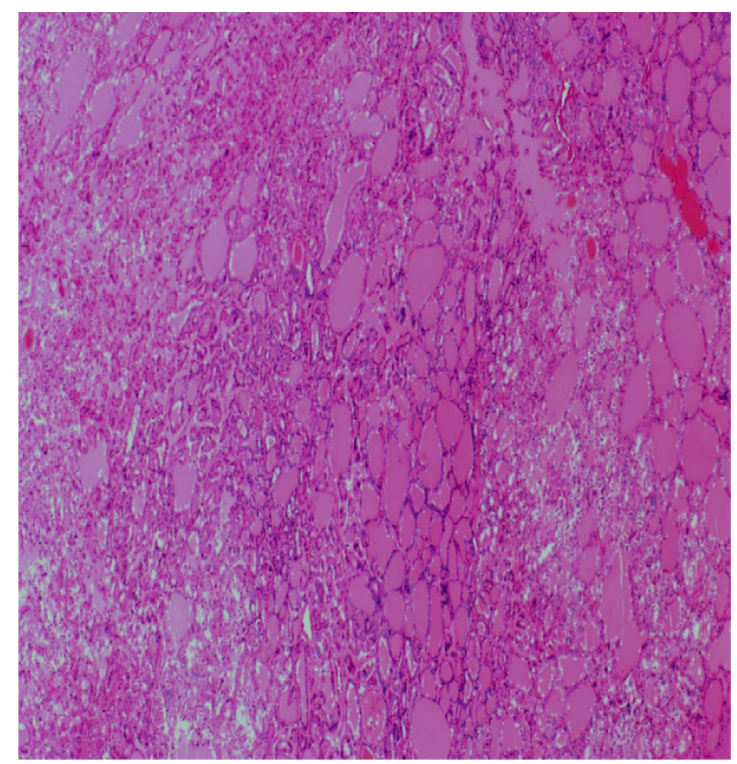

Figure 3 Histopathology of para-sagittal dural lesion showing follicular pattern with numerous colloid-filled follicles with characteristic nuclear features of papillary carcinoma (enlarged and elongated nuclei and nuclear grooves). during the sixth decade of life, and mean duration between initial diagnosis and calvarial metastasis was 72 months, which is in agreement with the previously published reports. ${ }^{3,8-11}$ Also, similar to the reported literature, follicular variant of PTC was seen in our patient..$^{3,5,8,10}$ Follicular variant PTC is known to have higher tendency to metastasize via hematogenous pathway than classic PTC. ${ }^{12}$

Calvarial metastasis with direct dural involvement is not uncommon. In one autopsy series, dural involvement secondary to calvarial metastasis with intracranial extension was seen in $25 \%$, and true dural metastases were observed only in $1 \%$ of cases. ${ }^{13}$ To date, true dural metastasis from PTC is not known, and to the best of knowledge, our patient is the first case with true dural metastasis from PTC.

Diagnosis of calvarial and true dural metastases is challenging as these lesions are often mistaken as meningiomas. Noninvasive diagnostic techniques, including CT/magnetic resonance imaging, are essential for detecting, localizing, and assessing the extension of these lesions. However, an incorrect diagnosis is also likely to occur if it is based on the radiological findings, without a tumor biopsy. ${ }^{8}$ In such cases, histopathological diagnosis along with immunohistochemistry should be made for definitive diagnosis.

The optimal management of calvarial and dural metastases is yet to be outlined. There does, however, appear to be a clear consensus that surgical resection is advantageous. However, complete surgical resection is often difficult in some cases because of risk of bleeding from these hypervascular lesions, presence of adjacent vital structures (brainstem, cochlea, cranial nerves, and corpus callosum), and risk of cerebrospinal fluid leak. Radical radiation therapy is another treatment modality that has been employed to control the calvarial and dural diseases either as an alternative to surgery for unfit patients or as an adjunct as in our patient. The effectiveness of radiation therapy is yet to be properly defined. ${ }^{9}$ Our patient was treated with sorafenib, as recent trials have shown that tyrosine kinase inhibitors (TKIs) produce progression-free survival of $\sim 1$ year (range: 7.7-19.6 months), especially in patients with BRAF V600E mutations. ${ }^{14}$

\section{Conclusion}

In conclusion, calvarial and dural metastases from PTC are extremely rare clinical entities. Surgical resection followed by postoperative radiotherapy is the treatment of choice. However, for such cases, multidisciplinary approach can prolong the disease-free and overall survival rates in patients with PTC. 
Table I Previously published cases with calvarial skull metastasis with intracranial extension and dural metastasis from papillary thyroid carcinoma

\begin{tabular}{|c|c|c|c|c|c|}
\hline Reference & Age (years)/sex & Symptoms & Site & Histopathology & Treatment \\
\hline Portocarrero-Ortiz et al ${ }^{3}$ & $6 \mathrm{I} / \mathrm{F}$ & Lump & Temporo-occipital bone & $\begin{array}{l}\text { PTC and follicular } \\
\text { variant }\end{array}$ & $\begin{array}{l}\text { Surgical resection and TSH } \\
\text { suppression }\end{array}$ \\
\hline Tazi el et al ${ }^{5}$ & $4 I / M$ & $\begin{array}{l}\text { Headache } \\
\text { and lump }\end{array}$ & $\begin{array}{l}\text { Temporo-occipital bone } \\
\text { and transverse dural sinus }\end{array}$ & $\begin{array}{l}\text { PTC and follicular } \\
\text { variant }\end{array}$ & $\begin{array}{l}\text { Surgical resection and } \\
\text { paclitaxel } \times \text { six cycles }\end{array}$ \\
\hline Nigam et al ${ }^{7}$ & $48 / F$ & $\begin{array}{l}\text { Headache } \\
\text { and lump }\end{array}$ & Occipitoparietal bone & $\begin{array}{l}\text { PTC and classic } \\
\text { variant }\end{array}$ & $\begin{array}{l}\text { Carboplatin }+ \text { doxorubicin } \\
\times \text { three cycles } \rightarrow \text { RT } \rightarrow \\
\text { carboplatin }+ \text { doxorubicin } \times \\
\text { three cycles }+ \text { zoledronic acid }\end{array}$ \\
\hline Li et al ${ }^{8}$ & $61 / F$ & $\begin{array}{l}\text { Headache } \\
\text { and lump }\end{array}$ & Fronto-parietal bone & $\begin{array}{l}\text { PTC and follicular } \\
\text { variant }\end{array}$ & RAI and TSH suppression \\
\hline Houra et al ${ }^{9}$ & $76 / F$ & $\begin{array}{l}\text { Headache } \\
\text { and lump }\end{array}$ & Fronto-parietal bone & $\begin{array}{l}\text { PTC and classic } \\
\text { variant }\end{array}$ & Surgical resection and RT \\
\hline Sisson et a $\left.\right|^{10}$ & $65 / F$ & Lump & Occipital bone & $\begin{array}{l}\text { PTC and follicular } \\
\text { variant }\end{array}$ & $\mathrm{RAI} \times$ three times \\
\hline Lin et al" & $75 / F$ & $\begin{array}{l}\text { Seizures and } \\
\text { painful lump }\end{array}$ & Occipital bone & PTC and classic & Surgery and RAI \\
\hline Present case & $65 / F$ & Lump & $\begin{array}{l}\text { Occipitoparietal bone and } \\
\text { para-sagittal dural metastasis }\end{array}$ & $\begin{array}{l}\text { PTC and follicular } \\
\text { variant }\end{array}$ & IMRT and sorafenib \\
\hline
\end{tabular}

Abbreviations: F, female; PTC, papillary thyroid cancer; TSH, thyroid-stimulating hormone; M, male; RT, radiation therapy; RAI, radioactive iodine; IMRT, intensitymodulated radiation therapy.

\section{Acknowledgment}

Written consent was given from the guardian and the patient before publication.

\section{Disclosure}

The authors report no conflicts of interest in this work. No grants or funds were received for this study.

\section{References}

1. Miyawaki S, Yamazaki R, Harada T, et al. Skull metastasis of thyroid papillary carcinoma. J Clin Neurosci. 2007;14(5):481-484.

2. Jouhar FS, Quadri A, Afandi B, Al Rawi S. Occult papillary thyroid carcinoma metastasis to the sacrum and the skull: an unusual presentation. Case Rep Med. 2014;2014:516549.

3. Portocarrero-Ortiz L, Garcia-Lopez R, Romero-Vargas S, et al. Thyroid follicular carcinoma presenting as skull and dural metastasis mimicking a meningioma: a case report. J Neurooncol. 2009;95(2):281-284.

4. Hamid HA, Gee KY, Muhammad R, Abd Rahman ZA, Das S. Dural metastasis mimicking meningioma: an interesting case. Acta Medica (Hradec Kralove). 2009;52(1):19-22.

5. Tazi el M, Essadi I, Errihani H. Thyroid carcinoma presenting as a dural metastasis mimicking a meningioma: a case report. $N \mathrm{Am} J \mathrm{Med} S \mathrm{Sci}$. 2011;3(1):39-42.
6. Kutluhan A, Yalcıner G, Bozdemir K, Ozdemir E, Tarlak B, Bilgen AS. Papillary thyroid carcinoma with metastasis to the temporooccipital skull: a case report. Kulak Burun Bogaz Ihtis Derg. 2012;22(3): 160-163.

7. Nigam A, Singh AK, Singh SK, Singh N. Skull metastasis in papillary carcinoma of thyroid: a case report. World J Radiol. 2012;4(6): 286-290.

8. Li X, Zhao G, Zhang Y, et al. Skull metastasis revealing a papillary thyroid carcinoma. Chin J Cancer Res. 2013;25(5):603-607.

9. Houra K, Vucic M, Cupic H, Kovac D, Cerina V. Osteolytic skull metastasis with dural involvement from a papillary thyroid carcinoma. Coll Antropol. 2011;35(3):919-922.

10. Sisson JC, Dewaraja YK, Wizauer EJ, Giordano TJ, Avram AM. Thyroid carcinoma metastasis to skull with infringement of brain: treatment with radioiodine. Thyroid. 2009;19(3):297-303.

11. Lin KD, Lin JD, Huang HS, Jeng LB, Ho YS. Skull metastasis with brain invasion from thyroid papillary microcarcinoma. $J$ Formos Med Assoc. 1997;96(4):280-282.

12. Salajegheh A, Petcu EB, Smith RA, Lam AK. Follicular variant of papillary thyroid carcinoma: a diagnostic challenge for clinicians and pathologists. Postgrad Med J. 2008;84(988):78-82.

13. Tagle P, Villanueva P, Torrealba G, Huete I. Intracranial metastasis or meningioma? An uncommon clinical diagnostic dilemma. Surg Neurol. 2002;58:241-245.

14. Gruber JJ, Colevas AD. Differentiated thyroid cancer: focus on emerging treatments for radioactive iodine-refractory patients. Oncologist. 2015;20(2):113-126.

\section{Publish your work in this journal}

The International Medical Case Reports Journal is an international, peer-reviewed open-access journal publishing original case reports from all medical specialties. Previously unpublished medical posters are also accepted relating to any area of clinical or preclinical science. Submissions should not normally exceed 2,000 words or

\section{Dovepress}

4 published pages including figures, diagrams and references. The manuscript management system is completely online and includes a very quick and fair peer-review system, which is all easy to use. Visit $\mathrm{http}: / / \mathrm{www}$.dovepress.com/testimonials.php to read real quotes from published authors. 